\title{
Research on Technology Leapfrogging Strategy of Chinese Traditional Manufacturing Latecomers
}

\author{
Jiaojiao Guo* and Haijun Lu
}

\author{
School of Economies and Management, Beijing Jiaotong University, China \\ ${ }^{*}$ Corresponding author. Email: $20120691 @$ bjtu.edu.cn
}

\begin{abstract}
With the rapid development of science and technology, many enterprises have become industry leaders by applying advanced technology. In order to achieve the goal of catching up with developed enterprises in technology level and enterprise status, latecomers try to catch up with developed enterprises in various ways, and technological leapfrogging is an effective way to catch up. Compared with the traditional manufacturing industry in China, the overall level of technology is relatively low, and almost all of the core technologies used depend on imports. Therefore, China is facing an urgent problem of technological leapfrogging and catching up. In this paper, in order to put forward suggestions on the way of technological leapfrogging in Chinese traditional manufacturing industry, this paper focuses on the strategy of technological leapfrogging in traditional Chinese manufacturing industry on the basis of scholars' research.
\end{abstract}

Keywords: Latecomer enterprise, Technology leaps, Chinese Traditional manufacturing industry.

\section{INTRODUCTION}

Since the application of technology in the world, science and technology has gradually become an important determinant of regional and national economic development. After entering the 21st century, the technology gap between countries is more reflected in their comparative advantages. In this era, the high-tech industries represented by biotechnology, aerospace, new energy exploitation and application are developing rapidly. Therefore, whether it is for a country to improve its international competitiveness or for the survival and development of an enterprise, the development of science and technology is of great significance Innovation and development are crucial. Compared with developed countries and regions, some developing countries and underdeveloped areas have a certain gap in the level of scientific and technological development, so they try to catch up with developed countries and regions by means of technology "leapfrogging". China is now facing an urgent problem of technological catch-up. As the basis of China's national economy, the technological development level of manufacturing industry affects the development speed of China's economy. The overall technology level of China's traditional manufacturing industry is relatively low, the core technology used relies on import, and the investment in innovation funds is insufficient, which leads to a big gap with the world's technological development level. Therefore, China's traditional manufacturing industry is facing more urgent technological leapfrogging and catching up.

\section{LITERATURE REVIEW}

Luc Soete [1] put forward the concept of "technological leapfrogging" for the first time. He studied the technological development mode adopted by the emerging industrialized countries in the world, and proposed that the late developing countries could take advantage of the opportunity window of technological development and realize technological leapfrogging through continuous imitation. Gallagher [2] pointed out that the process of technological leapfrogging is the process of enterprises' technological accumulation. In the process of technology accumulation, the technological level can be continuously improved, and new technological knowledge is constantly produced and applied, so as to continuously improve the innovation ability and realize the technological leapfrogging. 
In China, the research on technology leapfrogging started late. Ma Qingguo [3] proposed the definition of "technological leapfrogging", that is, if the technology late developing enterprises can obtain higher technical performance improvement than the technology first developing enterprises in the previous corresponding stages, it is said that the late developing enterprises have technological leapfrogging. Han Junhua [4] and others believe that backward national enterprises can achieve technological leapfrogging through mergers and acquisitions of other enterprises, and require that the technological knowledge of the enterprises of both sides of the merger and acquisition have a high degree of relevance, which can realize the technology integration after merger and acquisition. Chen Yuanying [5] studied the conditions and practical problems of enterprises to achieve cross industry technological leapfrogging through $M \quad \& \quad A$ integration, and proposed that $\mathrm{M} \& \mathrm{~A}$ integration is conducive to the rapid realization of cross industry technological leapfrogging. Hu pan [6] and others used system dynamics modeling to obtain the evolution path of innovation capability of local manufacturing enterprises in the process of technological leapfrogging. The path characteristics include not only the continuous catch-up path based on capacity accumulation, but also the leaping pursuit path based on capability platform transition.

Scholars at home and abroad have made in-depth research on the concept, conditions and types of technological leapfrogging, but there are few studies on how to carry out technological leapfrogging in Chinese traditional manufacturing industry.

\section{RELATED CONCEPTS AND RELATIONS OF TECHNOLOGICAL LEAPFROGGING}

\subsection{Latecomers}

Compared with the first mover, latecomer is a concept that describes the relative development level among enterprises. The first mover refers to the enterprise that takes the lead in obtaining technological and market advantages in the process of enterprise development. In contrast, most scholars believe that latecomers refer to the developing countries which are faced with technical and market disadvantages in the process of development. The disadvantage of technology mainly refers to that the enterprise lags behind the first mover in terms of technical capacity, R \& D level and available technical infrastructure, while the market disadvantage mainly refers to the small and undeveloped market scale and incomplete market structure faced by the enterprise.

\subsection{Technological Innovation}

The process by which old technology can be replaced by new technology. Technological progress can be achieved through the following two aspects:

Technological innovation. Enterprises can increase human resources, material resources and other resources for independent technological innovation, through independent research and development of new technologies to improve the technical level of enterprises and achieve technological progress.

Technology diffusion. Technology diffusion means that individuals with advanced technology, such as enterprises and individuals diffuse technology to other individuals in a paid or unpaid way. By learning the advanced technology of first mover enterprises, enterprises can make up for and improve their own technical level to achieve technological progress.

\subsection{Technical Catch-up}

Technology catching up is a process of the position interaction between the first mover and the pursuer, which means that the technical level of the first mover is surpassed by the pursuer. In the process of technological development, there are some problems in the process of technological development. The market faced by enterprises and the resources invested in technology are different, which leads to the technology gap between different enterprises. This technology gap leads to the quality comparison of their products. The products of high-tech enterprises occupy a larger range of market, while the products of low-tech enterprises are difficult to compete for the high-end market. Therefore, the latecomers will take actions to achieve technological catch-up, and the technological gap will lead to technological catch-up.

\subsection{Technological Leapfrogging}

On the basis of various theories, this paper puts forward the concept of Technological Leapfrogging: technological leapfrogging is a way for latecomers or enterprises to catch up with and surpass technology. The latecomers go beyond some stages of technological development by applying breakthrough advanced technologies, and improve the technological level and competitiveness of enterprises through new products and new methods of application.

Technological leapfrogging is a process of catching up and learning. It takes technological progress as the approach, enterprises as the foothold, and improving the technical level to achieve the goal of technological catching up. If technological catching up is regarded as the goal of technological development of enterprises, technological 
leapfrogging can be regarded as a way to achieve technological catching up. In addition, technological innovation can also achieve technological catching up. Technology leapfrogging is not only to realize the substantial increase of technical ability and R \& D ability, but also the ultimate goal is to produce new products and explore new markets. Through technological leapfrogging, the market competitiveness of enterprises can be continuously improved, thus bringing greater economic benefits to enterprises.

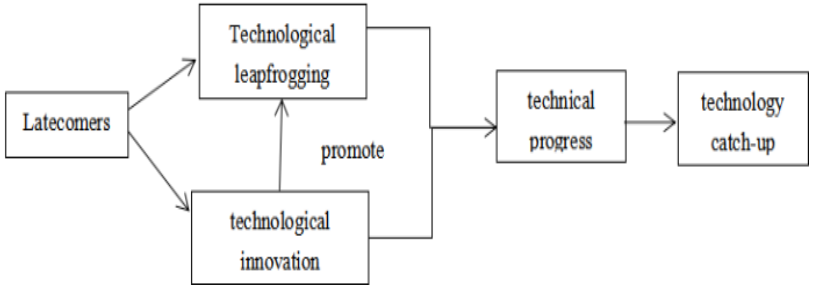

Figure 1 Related concepts of technology leapfrogging

The interrelationship of related concepts of technological leapfrogging is shown in Fig.1. Latecomers can achieve technological progress by means of technological leapfrogging or technological innovation, and achieve technological catch-up by accumulating the results of technological progress. Technological leapfrogging and innovation are not only parallel relations, but also can promote the realization of technological leapfrogging. Technological leapfrogging itself contains technological innovation. Since technological leapfrogging is the result of comparison between two main bodies, even if enterprises have achieved technological innovation, technological leapfrogging may not be achieved.

\section{ANALYSIS OF THE DEVELOPMENT STATUS OF TRADITIONAL MANUFACTURING INDUSTRY}

At present, although China's science and technology development level has made rapid progress, and some high-tech enterprises also occupy a certain leading position in the world, the proportion of China's overall manufacturing industry in the world is still not as good as that of developed countries, so China is still a traditional manufacturing country.

The development status of China's traditional manufacturing industry mainly includes:

The development is not balanced. China's traditional manufacturing industry is still in the position of low world industrial chain, which is vulnerable to competition from other low-cost countries, which leads to the reduction of its share in the world industry. Chinese traditional manufacturing industry has strong competitiveness in some special fields, mainly in the fields of offshore engineering equipment and communication equipment, while other fields show weak competitiveness due to the lack of core technology.

The mismatch between market demand and enterprise supply. Because the traditional manufacturing industry as a whole is at a lower level of manufacturing, it mainly pays attention to the existence of market demand, but not the quality of supply. The technical content of its products is not high, even the quality is low, and the competitiveness of products is not strong, which can't meet the special market demand, so that the supply and demand do not match.

The overall awareness of independent innovation is relatively weak. The innovation activities of traditional manufacturing industry in China are low, and the investment of innovation funds is low. The innovation mainly depends on the introduction of technology.

The management level of most traditional manufacturing enterprises is not high, the organizational structure of enterprises is not obvious, and the management system is not perfect.

\section{ADVANTAGES AND DISADVANTAGES OF CHINESE TRADITIONAL MANUFACTURING INDUSTRY IN TECHNOLOGICAL LEAPFROGGING}

The leapfrog development of Chinese traditional manufacturing industry means that the backward enterprises can catch up with the technological leaders through technological innovation. Due to the different characteristics of Chinese traditional manufacturing industry in terms of technical basis and economic development level, there are certain advantages and disadvantages in technological leapfrogging of Chinese traditional manufacturing industry.

\subsection{Disadvantages of Technological Leapfrogging}

\subsubsection{Labor Intensive}

Most of the traditional manufacturing industries in China are highly dependent on workers' labor, which is based on the advantage of population, and most of them work repeatedly, such as garment manufacturing industry. Some enterprises rely on low-cost labor to make profits. If they make technological leapfrogging, they will inevitably have to train workers, and even dismiss a large number of workers with the improvement of technical level. This kind of enterprise has higher input cost when it makes 
technological leapfrogging, which may cause social unemployment.

\subsubsection{Technical Disadvantage}

Chinese traditional manufacturing industry has a strong ability to accept new technologies, but the advanced technologies introduced are often not fully absorbed, and some key core technologies are not fully mastered. For the use of advanced technology is always subject to the source of technology enterprises, which makes enterprises have certain restrictions in technology leapfrogging

\subsubsection{Market Weakness}

China's traditional manufacturing industry is mainly faced with underdeveloped market and immature users. Market and user constraints form an invisible obstacle in the process of enterprise technology leapfrogging.

\subsubsection{Lack of Innovation Ability}

China's traditional manufacturing industry mostly treats technology imitation, which is difficult to digest and absorb, and its independent innovation ability is weak, and its R \& D capability lags far behind the enterprises in developed countries. Therefore, it is difficult to realize the real technological leapfrogging only by following the technology.

\subsection{Advantages of Technological Leapfrogging}

Due to the inability to bring considerable excess profits, developed countries rarely restrict the technology export of traditional manufacturing industries, but concentrate their efforts on high and new technologies in order to maintain their advanced technological advantages. This will give some developing countries the opportunity to play the advantage of latecomers, which is mainly manifested in that they can shorten the time required for technological progress and promote the rapid improvement of technological level by introducing advanced technologies and successful application experience of the first developing countries.

The production cost of traditional manufacturing industry in developed countries is higher, while that in China has the advantages of resource cost and labor cost, which makes Chinese traditional manufacturing products have more price space and market competitiveness. We can rely on the cost advantage to develop the international market.

The traditional manufacturing industry in China has accumulated a certain amount of technology in the process of development. On this basis, the quality of traditional manufacturing products will be greatly improved by introducing technologies or enterprises' own research and development, and making breakthroughs in some key technologies.

In addition, China encourages China to create and actively build an innovative country. Therefore, the leapfrog development of China's traditional manufacturing industry is in line with the trend of China's scientific and Technological Development and can attract national and social investment.

\section{TECHNOLOGY LEAPFROGGING STRATEGY OF CHINESE TRADITIONAL MANUFACTURING INDUSTRY}

China is a backward industrialized country, and most of the industrialized manufacturing industries belong to the latecomers. China's traditional manufacturing industry is in the middle and lower reaches of the world industrial chain. Due to the division of labor in the world, the traditional manufacturing industry of China can only share a relatively small part of the profit sharing of the world manufacturing industry. In order to realize the leap from "made in China" to "created in China", China must adopt the strategy of technological leapfrogging to realize the leapfrog development of traditional manufacturing technology and improve its position in the world manufacturing industry chain. In addition, if China's traditional manufacturing enterprises want to improve their product competitiveness, they need to constantly improve their manufacturing technology and transform technology into the source of profits, Therefore, the strategy of technological leapfrogging is the general trend.

\subsection{Conditions for Technological Leapfrogging of Chinese Traditional Manufacturing Industry}

The technological leapfrogging of Chinese traditional manufacturing industry is not a temporary or short-term enterprise behavior, but a long-term and systematic enterprise strategy. In addition, China's traditional manufacturing industry is in the great environment of China's industrial industry, based on the Chinese market, so it needs to form certain conditions from the macro and market environment, especially the effective strategies and policies of the government.

\subsubsection{Internal Conditions}

First, a clear source of technology. The essence of technological leapfrogging lies in more advanced 
technologies, which should have a clear source of acquisition, that is, enterprises can acquire new technologies through certain channels. For Chinese traditional manufacturing enterprises, the sources of technology can be the purchase of advanced technology at home and abroad, technical cooperation with advanced enterprises, independent innovation of enterprises, etc.

Second, technology research and application equipment. Technological leapfrogging requires a certain technical basis, and more advanced technologies are needed in leapfrogging. Therefore, enterprises should have a tool base suitable for technological leapfrogging.

Third, technology digestion and absorption capacity. For Chinese manufacturing enterprises, it is very important to internalize the imported technology, and its technology adaptation and absorption ability determines the success or failure of technological leapfrogging.

\subsubsection{External Conditions}

First, the government's strategic guidance and policy support. China's traditional manufacturing industry is a latecomer in technological development, which needs to take advantage of the latecomer. If only relying on the market to adjust, it will not only slow down the development speed, but also limit the source of technology. Therefore, the government must strengthen strategic guidance and policy support.

Second, industrial restructuring and upgrading. China must vigorously develop high-tech industry and promote the overall structural adjustment of manufacturing industry. The development of high-tech industry can bring the environment of technology upgrading for manufacturing industry. The use of high-tech industry to promote the upgrading of traditional industry and promote the application of high-tech in traditional industry.

Third, pay attention to talents. Technology leapfrogging takes technology as its foothold. The development and use of new technology need high-tech talents. Excellent human resources are of great significance for technological leapfrogging.

\subsection{The way of Technological Leapfrogging of Chinese Traditional Manufacturing Industry}

According to the advantages and disadvantages of Chinese traditional manufacturing industry in technological leapfrogging, the following ways of technological leapfrogging are put forward

\subsubsection{The introduction of Technological}

Leapfrogging is the Main way of Technological Leapfrogging in Chinese Traditional Manufacturing Industry

China's traditional manufacturing industry has little investment in technological innovation and weak innovation consciousness. Most of the traditional manufacturing enterprises are small and medium-sized enterprises, which can't bear the huge cost of technological innovation. Therefore, for Chinese traditional manufacturing enterprises, the most convenient and rapid way of technological leapfrogging is technology introduction. The traditional manufacturing industry itself has a certain technological foundation. The most important step after technology introduction is to digest and absorb the new technology, integrate it with the technological basis of the enterprise itself, and try to make innovation and improvement on the basis of new technology in the process of continuous absorption.

\subsubsection{Independent and $M \& A$ Technology Leapfrogging}

Large enterprises in China's traditional manufacturing industry have strong financial strength and a certain sense of innovation, and can bear the $\mathrm{R}$ \& D cost of enterprise technological innovation. For this type of enterprise, we can take the way of independent research and development to develop new technology or through the acquisition of intangible assets of other enterprises to achieve technological leapfrogging.

\subsubsection{Cooperative Technology Leapfrogging}

Chinese traditional manufacturing enterprises can cooperate with other enterprises, universities and scientific research institutes to achieve technological progress. Cooperative technology leapfrogging is not limited by the scale of enterprises, but it can realize complementary advantages and reduce risks, so it is more practical for enterprises lacking independent innovation ability and technology introduction capital investment.

\section{CONCLUSION}

The late developing enterprises of traditional manufacturing industry in China can achieve technological progress through technological leapfrogging and technological innovation, and finally achieve the technological level to catch up with the developed enterprises. Based on the analysis of the current situation and development trend of Chinese traditional manufacturing industry, the advantages and disadvantages and leapfrogging strategy of Chinese 
traditional manufacturing industry technology leapfrogging are summarized as follows: introduction of the best, independent, merger and acquisition assistance, absorption and innovation.

Due to the limited ability of the author, there is no research on the internal and external environment and opportunity window required by technological leapfrogging. For the technological leapfrogging of Chinese traditional manufacturing industry, only the technological leapfrogging mode adopted by enterprises is involved. In the follow-up, pest environment analysis and Enlightenment research on technology leapfrogging failure of traditional manufacturing enterprises in China can be carried out.

\section{REFERENCES}

[1] Luc Soete. International diffusion of technology, industrial development and technological leapfrogging $[\mathrm{J}]$. World Development, 1985, (3):409-422.

[2] GALLAGHER K S. Limits to leapfrogging in energy technologies? Evidence from the Chinese automobile industry [J].Energy Policy, 2006, 34 (4):383-394.

[3] Ma Qingguo, $\mathrm{Hu}$ Longji. Definition of technological leapfrogging [J]. Scientific research management, 2007 (05): 9-17.

[4] Han Junhua, Wang Hongchang, Liu Bo. Research on technology merger, integration and innovation [J]. Scientific management research, 2018, 36 (01): 57-60.

[5] Chen Yuanying. Conditions and practical problems of merger and integration of technology leaping enterprises [J]. Modern commerce, 2018 (11): 105-106.

[6] Hu pan, Wang Gangyi, Yu Bo. System dynamics modeling and simulation analysis of innovation capability evolution of local manufacturing enterprises in the process of technological leapfrogging $[\mathrm{J}]$. Industrial technology economy, 2018, 37 (08): 68-77. 